\title{
The Research of the Relationship between Marketing Information Channel and Impression Like and Dislike for Tutorial Education
}

\author{
Chu-Pai Lee, Dong-Cheng Liu, Hei-Ming Chou, and Chin-Mei Lin
}

\begin{abstract}
This research is based on a Middle School Tuition Class in Taichung City. We discuss the impact of different marketing information channels on the enrollment performance of cram schools. With the help of the author's many years of cram school management experience, we design many different marketing information channels, and investigate the results of each marketing information channel's impact on consumers by questionnaire. We have compiled the conclusions of this study and put forward some appropriate suggestions for the help and reference of the tutoring industry and related research scholars.
\end{abstract}

Index Terms-Extra-curricular classes, marketing methodology \& advertising strategies, questionnaire analysis.

\section{INTRODUCTION}

\section{A. Research Background, Issues and Purpose}

\section{1) Background of buxibans}

In Taiwan, going to after-school learning centers is part of most students' daily life. The purpose of buxibans has changed over time. In the past, attending buxibans was intended mostly for academic progression, which could last from elementary school age until it was time to prepare for graduate entrance exams.

During the period of economic growth known as the "Taiwan Economic Miracle", parents were too busy working to take good care of their children's academic performance, which boosted the buxiban industry. Moreover, due to the rapid increase in number of buxibans, and the consequential increase in competition, parents and students increasingly placed a higher value on academic qualifications, causing the industry to prosper even more extensively. According to Global Views Monthly [1], the Ministry of Education had a third party collate a statistic on the number of buxibans in January 2017, there were 18,492 after-school learning centers nationwide. This was 4 times more compared to the previous statistic taken 15 years before earlier in 2002. To put that in

Manuscript received February 5, 2019; revised March 26, 2019. This work was supported in part by the Dongcheng Wenli Short-term Tuition Class. The Research of the Relationship between Marketing Information Channel and Impression Like and Dislike for Tutorial Education.

Chu-Pai Lee, Dong-Cheng Liu, and Hei-Ming Chou are with the National Taichung University of Education Master's Institute in 2018 and was admitted to the School of International Business Management (e-mail: bt1106092@yahoo.com.tw, bubu590818@gmail.com)

Chin-Mei Lin was d with Home Economics School of Clothing Studies, Bunka Woman University, Japan (e-mail: cheri6688@ hotmail.com). perspective, this is 1.8 times more the number of convenience stores in the whole country.

2) The problems faced currently about buxibans in Taiwan

To relieve the pressure of education, the government has made a number of reforms to encourage extra-curricular activities such as music class, dancing or chess. With so many changing practices, buxibans had to quickly incorporate these classes into their own curriculum. These kinds of extra-curricular classes are now considered necessary in the eyes of many parents.

The government has inadvertently promoted the atmosphere of "cramming". So the tutoring class flourished. Many started to wonder if exams were actually necessary to progress academically and began asking if "cramming" negatively impacted mental and physical wellbeing. As a result, it became more difficult for buxibans to enroll new students. According to a survey from the Management Information System of the Ministry of Education, 9,041 "short-term supplementary learning centers", i.e. buxibans, had closed down between 2004 and 2014. Despite more buxibans opening, those with poor enrollment rates and a perception of being substandard are easily phased out.

Even more devastating to the buxiban industry was the Yi-Han Lin scandal which happened in 2017. It publicly tarnished the reputation of buxibans which led to a decline in the percentage of parents who consider buxibans trustworthy. Because of these challenges, owners of buxibans have had to adapt more effective and innovative marketing methods to maintain high enrollment rates and keep their doors open.

\section{3) The purpose of this research}

The purpose of this study is to investigate where the students do or student's parents know the Buxibans information from. And we also want to know parental preferences about the information from Media-Based Marketing Methods of Buxibans. Where do they know this Buxiban, and how's the feel when they know that Buxiban? Would they want to have a audition to the Buxibans? This resreach want to know which way of The Media-Based Marketing Methods infulence the consumers more? And which kind of the Admissions advertisement parents and students like by Buxibans. We want to know the factory of that. After our research, we can apply in the enrollment behavior of cram schools.

\section{B. The Aim of the Study}

The aims are to:

1) Find out which media-based marketing method is the 
most effective at reaching new customers.

2) Find out which media-based marketing method customers most prefer.

3) Investigate customers' impressions and preferences regarding different advertisements with survey questionnaires.

4) Conclude the most effective media-based marketing method with the results of the surveys to further assist buxibans with effectively increasing enrollment rates.

\section{The Media-Based Marketing Methods of Buxibans}

There are several main marketing and advertising methods for buxibans in Taichung as follows:

\section{1) Outdoor billboards}

Outdoor billboards are installed to be seen on main roads. They not only advertise information in an effective way, but also create and strengthen first impressions.

\section{2) TV commercials}

TV commercials can make a lasting impression on customers. However, prime-time slots which have the most viewers also cost a great deal of money. Thusly TV commercials may get a low price-performance ratio and make little to no profit for the buxiban. This makes TV commercials financially risky and buxibans are less likely to spend this much money upfront.

\section{3) Mobile billboards on buses}

In order to target parents, the route of buses with mobile-billboards needs to be carefully considered.

Because buses are mobile and do not stay in one place for long, the target audience is exposed to the advertisement for less time than a regular, static billboard. Mobile bus billboards may target pedestrians more effectively as it may be harder for people in cars and on scooters to reliably view them. To make this method effective, multiple bus advertisements might be required which, of course, significantly increases costs.

\section{4) Roadside banners on median strips}

Due to the limited space, roadside banners may only be able to show a little information. A lasting effect on drivers may be harder to achieve as they may be driving past roadside banners quickly. It may require multiple banners to have a significant impact on the drivers which correspondingly increases prices.

\section{5) Radio commercials}

Radio commercials allow easy access to audiences who regularly use radios such as long-time users or businesses. However with the rise of online music videos on-demand, radio audiences have shrunk and thus radio adverts reach fewer people.

\section{6) Magazine covers}

This is a HIGHLY problematic method as magazine advertisements are expensive and have a limited sales volume, so the audience reached is smaller. Although some minorities would still go purchase the publications, many people prefer online content via apps so it's possible that printed magazines, such as Cheers or CommonWealth Magazine, may disappear.

\section{7) Direct mail}

To help people protect their privacy, the "Personal Information Protection Act" was enacted by the government to prevent customers' personal information, including mailing addresses, from being accessed by companies.

\section{8) Commissioned deliveries of leaflets}

One risk of this method is that it cannot be guaranteed whether the deliverymen hired by the outsourcing contractors truly give out one leaflet per household. This method is expensive and we also don't know where potential customers live, so many leaflets may be wasted on households for whom the leaflet is irrelevant, for example those without children. This means that this method may be inefficient and finding relevant customers in this way may be like looking for a needle in a haystack.

\section{9) Printed newspaper advertisements}

Printed newspapers are becoming less popular and being replaced by digital versions or alternatives. They are significantly unpopular with younger consumers, perhaps because it's more convenient to download apps and click to read at any time. Older generations, who seem to make up the majority of the printed newspaper customer base, are unlikely to be interested in enrolling in buxibans. It may be more effective to target parents directly.

After considering the strengths and weaknesses of these marketing methods, leasing "outdoor billboards" seems to offer the best cost to performance ratio. They are the cheapest option and the static nature of the adverts mean that the local population will repeatedly see the advert. As long as the advert offers clear, relevant information, it is likely that the buxiban that is featured on the advertisement will remain in the forefront of the viewer's mind when considering enrolling somebody into a buxiban.

With regards to using outdoor billboards as primary marketing tools, there appears to be the following requirements to make outdoor billboards effective:

i. A good location for the billboard with lots of traffic.

ii. A reasonable cost to rent the wall space from a landlord.

Finding a space for a billboard that meets the above requirements is difficult. Calling landlords often to enquire as to the cost may help reduce the overall price. Despite this, the strengths of outdoor billboards seem to outweigh the difficulties, and leasing an outdoor billboard seems the most effective and cost-efficient method of advertising buxibans.

\section{Research Methods}

In this research, we use questionnaire to investigate the factors of Buxibans' consumers that they are interested in. We prepare two kinds of questionnaires. One of them is that what kind of cram school advertisement will impresses consumers mostly. Another one is which kind of cram school advertisements is popular among consumers. We would compare the factors of these questionnaires. And find the factors that affect the enrollment of the cram school. Summarize some innovative ways to promote the performance of cram schools.

\section{DOCUMENTARY DISCUSSION}

\section{A. The Definition of a Buxiban}

Private tutorial in buxibans is a part of social education in Taiwan, and thus the buxiban industry is one kind of social education enterprise [2]. According to Article 3 of the 
"Management Regulations Regarding Short-term Supplementary Learning Centers in Taipei", a "buxiban" means a learning center aiming at supplementing civilians' general knowledge, teaching practical skills or tutoring for the purpose of academic progression. It should conduct open enrollment, charge and give lessons at a public and fixed location, and have at least 5 students enrolled. Article 3 says that social education includes an extensive coverage such as the culture of nationality, family education, audio-visual education, cram classes and refresher courses, and so social educational institutes undertake these goals. Among all the projects, cram classes and refresher courses should follow the "Supplementary Education Act" [3]. It states that supplementary education can be divided into three types: supplementary compulsory education, supplementary advanced education, and short-term tutorial education. Citizens past the school age who have not yet received nine years of compulsory education shall receive supplementary compulsory education. Citizens who have already received nine years of compulsory education may receive supplementary advanced education. Citizens seeking to acquire general knowledge and skills may receive short-term tutorial education.

Therefore, supplementary education can be divided into three types: supplementary compulsory education, supplementary advanced education, and short-term tutorial education. The former two belong to regular school curricula, but the latter one belongs to non-school social supplementary education.

In article 6 of the regulation, it specifies that short-term tutorial education may be provided by schools, government organizations, foundations, or private parties. Short-term tutorial centers shall be divided into two categories: non-academic short-term tutorial centers and academic short-term tutorial centers. Courses shall last from one month to one year and six months. In Taiwan, "buxibans" are the most common methods to implement short-term tutorial education. The mission of supplementary education shall be to supplement the general knowledge of the nation's citizens, raise the nation's level of education, disseminate practical skills, foster the development of vigorous and well-rounded citizens, and spur social progress.

\section{B. The Definition of Advertising}

Advertising [4] is a kind of marketing act in a restrictive sense, used to persuade the audience and arouse motives to purchase. They are also known as commercials. On the other hand, advertising is more than that in a broadest sense; it's propaganda of conveying messages and promoting awareness. No matter whether it's related to commerce or it is aimed at generating profits, as long as it's equipped with fundamental traits of advertising, it can be classified as an advertising activity. For example, to enhance the support for politics or awareness, there are ads which campaign for public welfare. Every advertisement is composed of two parts: the information and the media. The advertising is merely part of all marketing strategies.

Aside from advertising, there are other marketing strategies including propaganda, public relations (PR), promotion, undercutting and so on. In 2010, the costs of ads estimated by advertising companies in the US amounted to around \$142B USD, and the costs of the advertisements worldwide amounted to around \$467B USD. An appropriate amount of advertising enables the public to understand the traits of products; however, in general, too much of it can arouse annoyance and antipathy.

On the basis of the transmission range, advertisements can be classified into 3 types: local advertisement, nationwide advertisement and international advertisement. The local advertisement refers to ads that are only broadcasted in a certain area. Due to the smaller transmission range and smaller markets, targeted consumer groups are relatively explicit and focused, and thus the advertising clients are mostly retailing business enterprises and local industrial enterprises. Compared to nationwide and international advertisements, local advertisements have 2 unique traits:

1) The transmission range for such ads is smaller and so is the market range. Local media are often chosen, such as local newspapers, radio, TV channels, signpost ads, electronic marquees and so on.

2) Such ads are mostly enacted in concert with a "concentrated marketing strategy". The main purpose of these ads is to prompt people to make use of local products or purchase at certain stores.

\section{Brand Image}

Brand image is a mental association for brands and the recognition of the brand in the eye of customers, which can be combined or linked with the products customers access to or the value of service experiences.

Functionality is also included in the brand image, which means the actual feelings and experiences the customers have for the products. For all buxibans, brand image is very important; it's the first impression for potential customers and also one of the factors that the public accredit.

\section{Marketing Service}

According to Shuen-Ching Hong [5], marketing service is comprised of external marketing, internal marketing and interactive marketing, which combine closely to one another. The act of marketing is a sort of service consisting of promise and realization. After achieving consensus on a reasonable and available service with customers with external marketing, we have to prepare to be capable of fulfilling those commitments with internal marketing. Internal marketing ensures that the front-line customer service personnel show professionalism and mildness when interacting with customers.

\section{E. Performance of Enterprise (Operation Performance)}

According to Jia-Bing Gao [6], it is important to point out that the criteria of operation performance are not the same across different organizations due to the different requirements of those companies and organizations. To assess performance, the operation results and resources formerly used can be compared, which can be a guide for future operation strategies and how to allocate resources. Not only do the buxibans attach importance to financial performance, but they also have to enhance customer satisfaction; in addition, joining charitable activities and maintaining community relationships can help upgrade the quality of the 
business operation.

\section{F. Performance of Enterprise (Operation Performance)}

\section{1) The definition of the method of questionnaire survey}

The method chosen for this study was questionnaires. This method means to implement a set of consistent stimuli (e.g. questions) on a group of representative answerers. In accordance with the reactions (or answers) received from the answerers (i.e. our sample), attitudes or reactions to certain questions of the represented population (the entire aggregation) are able to be estimated. The method is used in academic studies as well as public or customer opinion surveys, marketing investigations and other fields. [7] To design the questionnaire, we must first define the terms "population" and "sample."

"Population" is the target group that needs to be studied. In general, before the researchers have drawn up the questions and aims of the study, they should clarify and fully understand who the target group are in advance. Take a study which was titled as "Study in Students' Allowance for Kaohsiung Yiang-Guan Elementary School" from a university research worker, for example. If there are 2051 students in Kaohsiung Yiang-Guan Elementary School, then the 2051 students are called the "population". However, due to the limited research funding, time, difficulty of practice and the rest, researchers often pick a group of representative people, who are called the "sample", to be the targets who get conducted with the sampling survey in an effective way. The survey result obtained from sampling can be used to infer the outcome of studies from the "population".

\section{2) The reliability and validity of the questionnaires}

The reliability and validity are important norms that indicate whether the information and resources collected are reliable and correct, which puts a huge effect on the whole study. These two terms are separately specified below:

\section{a) The meaning of reliability}

Reliability refers to the stability of a questionnaire construction. That is to say, a reliable questionnaire must show the same or similar results when a same group of people are tested at anytime and anywhere. This makes the results trustworthy. For example, if Ming's temperature was taken with an ear thermometer one minute ago and received the result of " $40 \mathrm{C}$ ", and we received another reading at " $37 \mathrm{C}$ " one minute later, we would say that the thermometer is not stable. This is because the temperature of a human's body doesn't change that quickly without medication. Therefore the results of these tests are unreliable and we cannot depend on the results. We can even say that the ear thermometer may be malfunctioning and shouldn't be used again.

\section{b) The meaning of validity}

A valid questionnaire means that the questionnaire is constructed effectively. The indicator of a valid questionnaire will show whether the questionnaire was capable of detecting problems or issues within the study. For example, a teacher wants to test students' learning on a certain unit of mathematics thusly makes a test paper. After results come out, it is discovered that the scores of well-learning students are not high, but the scores of students who learn badly are higher, which means that the paper is poorly designed and is invalid.

\section{THE DESIGN AND METHOD FOR THE STUdy}

\section{A. Obtaining the Information Sources}

In the study, we design our method as Fig. 1. The parents of students in the buxiban were asked how they found out about the buxiban. Next, the enrolled students were also asked in which way they and their parents found out about the buxiban.

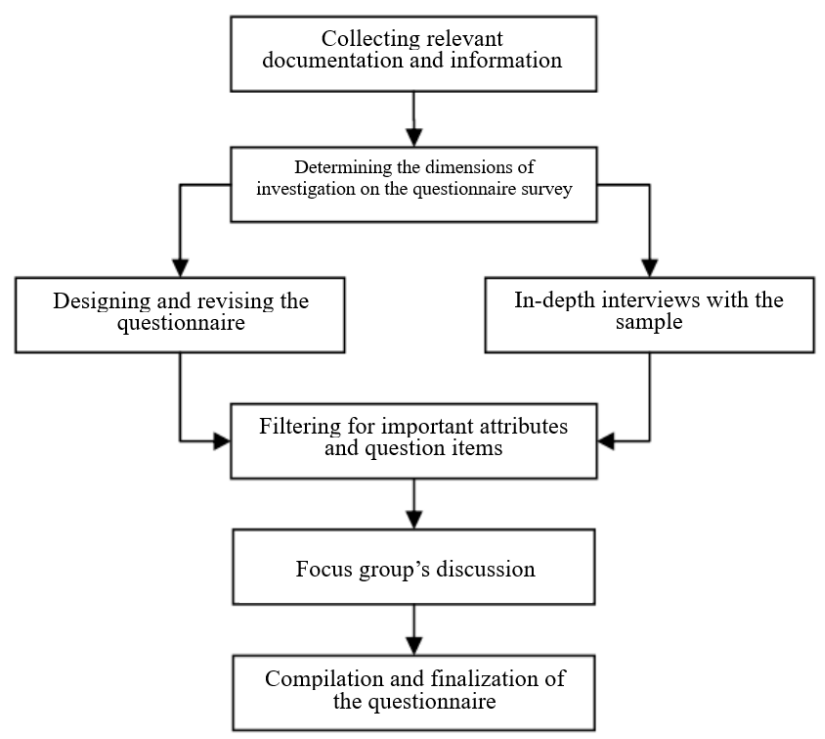

Fig. 1. The process of designing a questionnaire for study [8].

\section{B. Impressions of Reception of Information}

The first set of questions study aimed to judge how often parents received information about buxibans, or the buxiban industry, and in which ways as defined previously, such as:

1. Outdoor billboards

2. TV commercials

3. Mobile bus billboards

4. Roadside banners on median strips

5. Radio commercials

6. Magazine covers

7. Direct mail

8. Commissioned delivery of leaflets

9. Newspaper advertisements

Parents were asked about how impressed they were with the advertisements that they received. The Likert scale formed the basis for the responses which ranged from "strongly disagree" to "strongly agree". Each response on the scale was attributed a point score between 1 and 6 . The higher the score is, the more the parent was impressed with the media-based methods used to propagate information about the buxiban.

To extend the scope of the questionnaire, the parents' impressions of the buxiban were studied with an additional 5 questions: the name of the buxiban, the perceived quality of it, opinion of the teaching faculty, curriculum and school performance, etc. The Likert scale was used again with the same system of 6 options ranging from "extremely dissatisfied" to "extremely satisfied". The higher the score was, the better the parents' opinion of the buxiban was; conversely, the lower the score was, the poorer the parents' 
opinion of the buxiban was.

\section{Preference for Reception of Information}

The second set of questions study aimed to judge how parents preferred to receive information and questions were designed around the following methods. At first, parents were asked how they felt about the following methods generally speaking:

1. Outdoor billboards

2. TV commercials

3. Mobile bus billboards

4. Roadside banners on median strips

5. Radio commercials

6. Magazine covers

7. Direct mail

8. Commissioned delivery of leaflets

9. Newspaper advertisements

The 6-point Likert scale was used once more for the measurements; from "extremely dissatisfied" to "extremely satisfied", with each response being attributed a point between 1 and 6 respectively. The higher the score is, the more the parents liked the given media-based method in general.

To compare, the parents were then asked how much they felt about the given methods used by their specific buxiban, regarding the same 9 methods above, if used at all. The options ranged from "negative" to "positive", and one to six points were given respectively. The higher the score was, the more positive the parents felt about their specific buxiban's usage of a given method; conversely, the lower score meant that the parents felt their specific buxiban's use of a given method was objectionable.

\section{Marketing Service}

For the study, Excel was put to use as an analytical tool for the retrieved questionnaire data. In accordance with current constructs of the study, "scale reliability and validity" is made and hypothesis testing done.

The relevant methods of information analyses are as follows:

\section{1) Descriptive statistics analysis}

The dispersion of the sample is described in the method of descriptive statistics analysis; the overview of the data received from the analysis is under observation and serves as the basis of further study of statistical analysis.

\section{2) Reliability analysis}

In the study, Cronbach's alpha is applied to measure the degree of consistency and stability of every dimension of the survey. A scale with validity means a measuring procedure yielding consistent results on repeated administrations of the scale under any different conditions. As a rule of thumb, Cronbach's alpha requires a reliability of 0.7 or higher for the results to be considered reliable [9].

Some other scholars like Chiuan-Yung Chen [10] consider a reliability of more than 0.7 excellent, while a reliability of less than 0.35 poor or unacceptable.

\section{3) Validity analysis}

Validity is considered to be the degree of probability to which the tool (the scale) actually measures what it claims to measure. Only scales that accurately reflect, assesses and capture the concept which we are trying to measure can be considered valid.

Content validity (expert validity) is adopted in the study since it is used in scholarly work, in scales that have been examined by professors in HR Graduate Programs, and executives of companies. This makes the scales of this study equipped with content validity.

\section{ANALYSIS OF INVESTIGATION}

\section{A. Results of the Statistics(Calculation)}

The main research targets of this paper are the parents and students of buxiban A in Taichung. 100 copies of questionnaires were given to the parents of buxiban A. The overall recovery rate amounted to $98 \%$, which means 98 copies were retrieved.

With the classifications of personal data, the sample structure of the questionnaire survey is as Table I $60 \%$ of respondents were female parents and $40 \%$ were male. $80 \%$ of the total responses were from parents aged 35 to $45.70 \%$ of respondents possessed an associate degree or bachelor degree."

TABLE I: THE STRUCTURE OF THE ANALYSIS SAMPLE

\begin{tabular}{|c|c|c|c|}
\hline Property & Category & Number of Times & Valid Percentage \\
\hline \multirow{2}{*}{ Sex } & Male & 39 & $39 \%$ \\
\hline & Female & 59 & $59 \%$ \\
\hline \multirow{6}{*}{ Age } & Under 30 & 2 & $2 \%$ \\
\hline & $31-35$ & 7 & $7 \%$ \\
\hline & $36-40$ & 41 & $41 \%$ \\
\hline & $41-45$ & 37 & $37 \%$ \\
\hline & $46-50$ & 8 & $8 \%$ \\
\hline & Over 50 & 3 & $3 \%$ \\
\hline \multirow{3}{*}{$\begin{array}{c}\text { Academic } \\
\text { Performance }\end{array}$} & $\begin{array}{l}\text { Associate Degree } \\
\text { (or below) }\end{array}$ & 15 & $15 \%$ \\
\hline & Bachelor's Degree & 68 & $68 \%$ \\
\hline & $\begin{array}{l}\text { Master's Degree } \\
\text { (or higher) }\end{array}$ & 15 & $15 \%$ \\
\hline
\end{tabular}

\section{B. Descriptive Statistics Analysis}

The results indicates that most of the parents and students got the information about buxiban A through "outdoor billboards", followed by recommendations from friends, relatives, neighbors as the second highest response. From this we know that in order to publicize a brand of buxiban, "outdoor billboards" are still necessary; however, this is only if the buxiban attains "good achievements/results" will the students and their parents be motivated to go to the buxiban. As for other marketing methods, in the eyes of the parents and students, other methods are less noticeable for them.

In the aspect of innovative marketing, although most students and parents tend to surf the internet or use smartphones for at least 6 hours in a day, they dislike seeing the internet advertising. Although internet advertising makes a vivid impression, most internet users don't like to see it. It is accompanied by bad feelings that consumers may then associate with the buxiban's brand.

Even though the internet is a new technology that is able to satisfy innovative marketing skills, it's still quite easy to make mistakes with it. 
The results also showed that students and parents like to see academic results shown in the advertising information the most, with course materials as the second highest element that parents like to see in the adverts. This shows the importance of "true performances" to a buxiban's success via enrollment. It is easier to enroll new students when there is a positive reputation surrounding the academic success of the buxiban's other students. Reputation therefore plays a big part too.

The most important part of the buxiban for the parents are that buxibans prioritize communication with the parents. Interactions must help the parents understand the learning progress of their children.

From all the statistical results above we can see that the methods of "outdoor billboards" and "word-of-mouth" are the favorite way parents and students to receive information about buxibans. Successful enrollment depends largely on word-of-mouth, spread by family, relatives or friends of the successful students of a buxiban. What's more, excellent academic performances and the great communication with parents are also selling points for the buxiban.

\section{Reliability Analysis}

On the survey questionnaires there were 5 sections about enrollment marketing with a total of 32 questions across the whole questionnaire. Each section is composed of several declarative sentences, which the parents then marked their agreement or satisfaction with. In theory, the higher the internal consistency between the questions in an section is, the more reliable the results and conclusions. are, as we see in Table II.

TABLE II: CRONBACH'S ALPHA

\begin{tabular}{|c|c|c|c|}
\hline \multicolumn{3}{|c|}{ TABLE II: CRONBACH'S ALPHA } \\
\hline $\begin{array}{c}\text { Items } \\
\begin{array}{c}\text { The impression of } \\
\text { the receptions of } \\
\text { information }\end{array}\end{array}$ & $\begin{array}{c}\text { Number of } \\
\text { Items }\end{array}$ & Cronbach's $\boldsymbol{\alpha}$ & $\begin{array}{c}\text { Cronbach's } \boldsymbol{\alpha} \text { if } \\
\text { Item Deleted }\end{array}$ \\
\hline $\begin{array}{c}\text { The preference of the } \\
\text { receptions of } \\
\text { information }\end{array}$ & 6 & 0.848 & 0.849 \\
\hline $\begin{array}{c}\text { Information needed } \\
\text { other than Enrolling }\end{array}$ & 10 & 0.868 & 0.871 \\
\hline Needs of Marketing & 4 & 0.901 & 0.905 \\
\hline Others & 6 & 0.869 & 0.868 \\
\hline
\end{tabular}

\section{CONCLUSIONS AND SUGGESTIONS}

\section{A. The Conclusion of the Study}

The discussions in the study are mainly about finding out effective and feasible media-based marketing methods for the buxiban industry, which finds itself in an incredibly competitive industry. The results of the questionnaire show that:

\section{1) Outdoor billboards are the most effective media-based marketing method}

"Outdoor billboards" stands out from other options in the survey, and is the most influential way to reach local groups of customers. Due to the long display time, and accompanied with an eye-catching and clear design, billboards tend to draw customers' attention easily. Billboards play an important role when publicizing and attracting local customers.

\section{2) Positive word-of-mouth and reputation encourages} enrollment

Aside from billboards, respondent parents' favorite marketing method was word-of-mouth and positive reputation generated by current students' parents. This further increases good impressions of the buxiban for the parents. That is to say, apart from the aspect of advertising, actual academic progress still plays a very important role for the buxiban to encourage confidence in the buxiban and generate a higher enrollment rate.

It's possible that parents may feel a sense of distance from the great successes of other students that the buxibans may be advertising. Thus, sometimes the belief that going to a buxiban can help get better grades are given by the acquaintances of the measurably successful students, when they themselves may not be improving.

Word-of-mouth from students' parents is able to be a further motivation for parents to enroll their children in the buxiban.

\section{3) Publicize with "outdoor billboards" plus word-of-mouth to increase enrollment rates}

Undoubtedly, publicizing with outdoor billboards is actually an effective way to advertise in local regions among groups of customers. It's relatively ineffective to use internet or other media-based methods. A true feeling of actual academic improvement as a result of the buxiban is conveyed by word-of-mouth from other parents the most, which becomes a motivation for the parents to enroll their children. It can make a breakthrough on the enrollments for the buxibans if they choose to publicize with outdoor billboards at first and secondly create good impressions via positive word-of-mouth, which will motivate parents to enroll their children.

The results of the study are also provided for others in related industries as well as reference for other academics

\section{REFERENCES}

[1] S.-Y. Chen, "Why has the number of buxibans tripled during the 20 years advocacy of educational reform?" Global Views Monthly, 2017.

[2] Y.-F. Chiu, The Quality of Service in Buxiban: Take an Officially Registered Buxiban in Pingtung for Example, Kaohsiung: National Sun Yat-Sen University, 2002.

[3] Official Laws and Regulations Retrieving System of Ministry of Education from Taipei. [Online]. Available: http://edu.law.moe.gov.tw/LawContentDetails.aspx

[4] N. Ning, 2009, The Advertising Lecture Course, 3rd ed. China: China Renmin University Press.

[5] S.-C. Hong, 2005, Marketing from the Heart: Service Tips to Aise 'Satisfied' up to 'Admired', Common Wealth Publishing: Taipei.

[6] J.-B. Gau, 2001, Study for Market Orientations of Non-Profit Organizations and Organization Performances - Taking a Cultural and Educational Foundation for Instance, Taipei: Graduate Program Department of Adult and Continued Education.

[7] J.-H. Choi, 2002, SPSS (PASW), Taipei: Wunanbooks.

[8] Y.-C. Lin and T.-T. Huang, 2007, Employee Opinion Survey and Diagnostic Analysis - Take an Information Electronics Manufacturing Company for Example, Taoyuan City: National Central University.

[9] J. C. Nunnally, 1978, Psychometric Theory, New York: McGraw Hill.

[10] C. Y. Chen, 2006, A Research of Relationships Among Job Expectation, Job Satisfaction and Turnover Intention of Direct Labor, Hsinchu: National Chiao Tung University. 


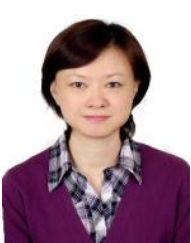

Chu-Pai Lee was born in China in 1965. She was admitted to the National Taichung University of Education Master's Institute in 2018 and was admitted to the School of International Business Management to become a graduate student and to study new areas.

Her employer is a government agency and has worked for more than 30 years. In one of the many commercial projects she works for, she is responsible for the student's dropout consulting business. She studied the relationship between primary and secondary school students and parents and the effect of learning, and thought that learning was very interesting.

Dong-Cheng Liu was born in Chiayi County Taiwan in 1965. Now he is currently pursuing master degree in EMBA of National Taichung University of education in Taichung City, Taiwan. His current research interests include cram school and advertisement.

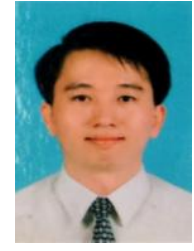

Hei-Ming Chou was born in Taiwan in 1970. He graduated from Yung Ta Junior College of Technology and Commerce and currently pursuing the master's degree in EMBA of National Taichung University of Education. He worked as a teller in Land Bank of Taiwan since 1996. His current research interest is about the financial sector.

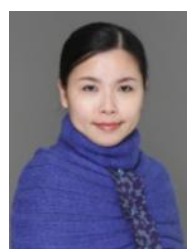

Chin-Mei Lin graduated with $\mathrm{PhD}$ in Home Economics School of Clothing Studies, Bunka Woman University, Japan. She is a professor and chairwoman in the Department of Fashion Design, Asia University, Taiwan. She is also a juror of the committee of National Institute of Translation and Compilation in examining textbooks of colleges and vocational high schools. And She is a referee of Executive Yuan. 